\title{
Detection of Infectious Bronchitis Virus and Specific Anti- Viral Antibodies Using a Concanavalin A-Sandwich-ELISA
}

\author{
ROBERTA V.M. BRONZONI, ${ }^{1}$ M. FATIMA, S. MONTASSIER, ${ }^{1}$ GENER T. PEREIRA, ${ }^{2}$ \\ NILCE M.S.Q. GAMA, ${ }^{3}$ VIVIANE SAKAI, ${ }^{1}$ and HELIO J. MONTASSIER ${ }^{1}$
}

\begin{abstract}
Concanavalin A-Sandwich ELISA (Con A-S-ELISA) was developed for the detection of infectious bronchitis virus (IBV) or chicken specific anti-viral antibodies. The antigen detection limit for the Con A-S-ELISA was $10^{5,1} \mathrm{EID}_{50} / \mathrm{mL}$. Three homologous and four heterologous IBV strains were similarly detected. This assay was highly effective in detecting the virus after infected tissue homogenates were passed once in embryonated chicken eggs, showing a good agreement with virus isolation technique. The Con A-S-ELISA was also used to measure anti-IBV chicken antibodies and showed a high coefficient of correlation $(r=0.85)$ and an agreement of $k=0.80$ with the commercially available Indirect-ELISA. The relative sensitivity and specificity between these two tests were, respectively, $\mathbf{9 2 . 8 6 \%}$ and $95.65 \%$ with an accuracy of $93.39 \%$. Thus, the Con A-S-ELISA proved to be able to detect alternatively homologous and heterologous IBV strains or specific chicken antiIBV antibodies, using the Con A as capture reagent of this assay.
\end{abstract}

\section{INTRODUCTION}

$\mathbf{I}$ NFECTIOUS BRONCHITIS VIRUS (IBV) is a member of Coronaviridae family which induces a highly contagious infection in chickens of all ages, causing great economic losses in the poultry industry of several countries (7). IBV contains three major structural proteins. The spike glycoprotein (S) is the outermost component of the virion and comprises two polypeptides, S1 and S2 with molecular weight of 84 and $92 \mathrm{kDa}$, respectively (6), which have many potential N-linked glycosylation sites (12). The membrane glycoprotein (M) is partially exposed at the virus outer surface, and has some glycosylation sites (12) and a molecular weight ranging from 27 to $36 \mathrm{kDa}$. The nucleocapsid protein $(\mathrm{N})$ is the major polypeptide of the nucleocapsid and is associated with viral RNA with molecular weight of approximately 52 $\mathrm{kDa}(5)$.

Various techniques are suggested for the diagnosis of IBV infection. The conventional viral isolation test (VI) in embryonated chicken eggs and immunofluorescence assay (IFA) are strongly recommended for the primary diagnosis of IB $(10,32,34)$. Nevertheless, these techniques are not exempted from some drawbacks, particularly the latter one, which is laborious, time-consuming and relatively expensive.

Enzyme Linked Immunosorbent Assays (ELISAs) have been developed and proved their efficacy, either for the detection of IBV antigen $(1,12,15,19,21,34)$, or antiIBV antibodies $(2,3,4,8,16,22,29)$.

Indirect ELISA methods need purified, semi-purified IBV particles, or recombinant IBV antigens for adsorp-

\footnotetext{
${ }^{1}$ Faculdade de Ciências Agrárias e Veterinárias, Departamento de Patologia Veterinária, Laboratório de Imunologia e Virologia, Universidade Estadual Paulista, Rodovia Prof. Paulo Donato Castellane, Jaboticabal, SP, Brazil.

${ }^{2}$ Faculdade de Ciências Agrárias e Veterinárias, Departamento de Ciências Exatas, Universidade Estadual Paulista, and ${ }^{3}$ Instituto Biológico, Bastos, SP, Brazil.
} 
tion to the microplate surface $(8,16,22,24)$. Alternatively, polyclonal or monoclonal anti-IBV capture antibodies have been adsorbed on the solid phase in sandwichELISA methods for trapping these viruses $(12,19,21)$. Whole virus purification requires propagating large quantities of virus in eukaryotic systems and whereas the most reliable serodiagnostic reagents require highly purified antigen, purification of IBV with its highly glycosylated spike protein is difficult and expensive (22). In addition to this, the protocols recommended for preparing polyclonal and monoclonal anti-IBV antibodies are even more complex and restricted. Hence, more rapid and accessible ELISA methods for IBV diagnosis which conciliate the capability to detect either IBV antigen or antibodies remain to be addressed.

ELISA methods using lectins to capture viral antigens have been developed for the diagnosis of some diseases. Lectins are proteins or glycoproteins derived from plants, animals, or microorganisms which are characterized by the ability to interact with carbohydrate moieties presents on the surface molecules of human, animal and plant cells, in addition to bacteria and viruses. They are stable and can provide an extraordinarily sensitive detection system of glycosylation and carbohydrate sites (14). The lectin-ELISA has been used for the diagnosis of pancreatic cancer, human immunodeficience virus (HIV) and feline immunodeficiency virus (FIV), revealing to be highly sensitive and feasible $(9,23,26,30)$. Despite their specificity and efficacy as glycoprotein binders, lectins have not been used on enzyme immunoassays for the diagnosis of coronaviruses, including IBV, or even other avian viral pathogens.

The present study aims to develop an alternative method for the detection of IBV antigens or chicken antiviral specific antibodies, using the same set of basic reagents and the format of the Concanavalin A-Sandwich ELISA (Con A-S-ELISA). This method was based on the specific interaction of Con A with terminal mannose groups of oligo and polysaccharides, as well as the findings that IBV glycoproteins $\mathrm{M}$ and $\mathrm{S}$ contain branched chains of linked oligosaccharides with a high mannose content (13).

\section{MATERIALS AND METHODS}

Viral antigens. The IBV reference strain Massachusetts 41 (M41) was propagated in the allantoic cavity of 10-day-old embryonated Specific Pathogen Free (SPF) eggs. The allantoic fluid (AF) was harvested $36 \mathrm{~h}$ after the inoculation and clarified. Approximately $1000 \mathrm{~mL}$ of infected AF was concentrated by polyethylene glycol (PEG-8000) $-\mathrm{NaCl}$ precipitation and purified by ultracentrifugation, using discontinuous and continuous su- crose density gradients $(2,27)$. IBV infected AF preparations and the purified virus suspension were clarified by centrifugation $(4,000 \times g$ for $15 \mathrm{~min})$ and the embryo $50 \%$ infectious doses $\left(\mathrm{EID}_{50}\right)$ were determined (20). IBV reference strains H120, H52, Arkansas 99 and IOWA 97, as well as two Brazilian field isolates (A034 and UEL236), were similarly propagated in embryonated chicken eggs.

Detector antibody. Chicken hyperimmune serum to IBV was prepared against purified IBV M41 strain in specific pathogen free (SPF) White Leghorn chickens. In brief, a group of six 14-day-old chicks was placed into positive pressure isolators and each chicken was given weekly, by the intra-ocular route, four doses of $10^{6.0}$ $\left(\mathrm{EID}_{50}\right)$ of purified IBV M41 strain diluted in $50 \mu \mathrm{L}$ of PBS $\left(0.14 \mathrm{M} \mathrm{NaCl}, 0.01 \mathrm{M} \mathrm{PO}_{4}, \mathrm{pH} 7.2\right)$. Two weeks after the last immunization, the birds were boosted, by intra-muscular route, with two doses of the purified and inactivated M41 strain emulsified in Freund's incomplete adjuvant. All chickens were anesthetized and bled two weeks after the last booster injection. The experiment was conducted in accordance with the Institutional Animal Care Committee from Faculdade de Ciências Agrárias e Veterinárias (UNESP).

Tissue samples for IBV antigen detection. Twentyeight samples from trachea or lung were collected at 7-14 days after experimental infection of commercial layers which were inoculated by ocular and intra-nasal routes with $10^{6.7}\left(\mathrm{EID}_{50} / \mathrm{mL}\right)$ of IBV (M41 strain). An additional set of 12 tissue samples was similarly collected from noninfected commercial layer chickens maintained in other isolator unit. All tissue samples were submitted to virus isolation test (VI) and passed thrice in embryonated chicken eggs, before they were considered negative, or positive, based on absence or presence of typical embryonic lesions induced by IBV, such as stunting, curling or death embryos (10). AF samples which were harvested from each egg passage were also assayed in Con A-SELISA. The experiment was conducted in accordance with the Institutional Animal Care Committee from Faculdade de Ciências Agrárias e Veterinárias (UNESP).

Chicken serum samples for antibody detection. (i) Field serum samples. Two sets of 40 serum samples were randomly collected, respectively, at 10 and 16 weeks age, from IBV vaccinated commercial layer chickens. These birds were vaccinated at 1,4 , and 8 weeks of age, with attenuated H $120 \mathrm{IBV}$ strain and re-vaccinated at 14 weeks age, with inactivated oil-adjuvanted IBV vaccine. An additional set of 41 chicken sera from different farms that reported suspected cases of IBV infection were used in this study. The serum samples were individually tested by Con A-S-ELISA and commercial I-ELISA. (ii) Chicken convalescent-phase serum. Twenty-four SPF White Leghorn chickens were divided into two groups of 
12 birds and housed into two positive pressure isolators. The first group was challenged, at 21 and 70 days of age, by eyedrop with $10^{6.7}$ embryo infectious doses $\left(\operatorname{EID}_{50}\right)$ of M41 IBV strain per bird and the second group remains non-infected as control group. Blood samples were collected from all chickens at inoculation and 5 days postinfection (PI), and thereafter at intervals of 2 weeks up to 63 days PI. The experiment was conducted in accordance with the Institutional Animal Care Committee from Faculdade de Ciências Agrárias e Veterinárias (UNESP). (iii) Positive and negative Anti-IBV reference sera. The anti-IBV negative reference serum consisted of a pool of six sera from adult White Leghorn SPF chickens, whereas a pool of six chicken which were hyperimmunized against IBV M41 strain sera, was used as positive reference serum. The experiment was conducted in accordance with the Institutional Animal Care Committee from Faculdade de Ciências Agrárias e Veterinárias (UNESP).

Con A-S-ELISA for antigen detection. A lectin capture system was used for detection of IBV. Con A was firstly adsorbed on the surface of ELISA microplate (Immunoplate Maxisorp F96; Nunc, Roskilde, Denmark) and after the addition of viral antigenic samples, a detector antibody was added to react with antigens from IBV trapped by the Con A. Firstly, the optimum concentrations of Con A and detector antibody were determined, in Sandwich-ELISA by checkerboard titration (2). Reagents were added in volumes of $50 \mu \mathrm{L} /$ well and the microplates were washed five times between each step with PBS plus $0.05 \%$ Tween 20 (PBST). The microplates were coated with Con A (Sigma Chemical Co., St. Louis, MO) diluted in PBS Ph 74 and incubated overnight at $4^{\circ} \mathrm{C}$. After washing, the microplates were blocked with a solution containing PBS supplemented with $10 \%$ skimmed milk (SM) and incubated for 45 min at $37^{\circ} \mathrm{C}$. Antigen test samples were diluted in twofold serial dilution in PBST-SM and then added in duplicate. After $1 \mathrm{~h}$ of incubation at $37^{\circ} \mathrm{C}$, the plates received an optimum dilution of anti-IBV chicken sera (detector antibody) prepared in PBST-SM. Following incubation of $1 \mathrm{~h}$ at $37^{\circ} \mathrm{C}$ and washing, rabbit anti-chicken $\operatorname{IgG}$ horse radish peroxidase conjugate (Sigma Chemical Co., St. Louis, MO), diluted in PBST-SM was added to each well, and the reaction was incubated for $1 \mathrm{~h}$ at $37^{\circ} \mathrm{C}$. After washing, the plates received the substrate solution containing 0.4 $\mathrm{mg} / \mathrm{mL}$ of ortho-phenylenediamine (Sigma Chemical Co., St. Louis, MO) and hydrogen peroxide $(0.006 \%)$ diluted in $0.1 \mathrm{M} \mathrm{Na}_{2} \mathrm{PO}_{4}$ and $0.1 \mathrm{M}$ citric acid buffer $\mathrm{pH}$ 5.0. After incubation for $15 \mathrm{~min}$ in the dark and at room temperature, the reaction was stopped by the addition of $2 \mathrm{M}$ hidrochloridric acid $(\mathrm{HCl})$. Non-infected tissue or allantoic fluid samples were used as a negative control antigen in each plate. Optical densities (ODs) were measured in an automatic ELISA reader (model-550; Bio-Rad, Her- cules, CA) at $490 \mathrm{~nm}$. ODs were transformed in sample to negative values $(\mathrm{S} / \mathrm{N})$, according to the formula: $\mathrm{S} / \mathrm{N}=$ $\mathrm{X} / \mathrm{Y}$, where $\mathrm{X}=$ mean of test sample $\mathrm{OD}$ and $\mathrm{Y}=$ mean of negative control sample OD. Test samples were classified by Con A S-ELISA as positive when their $\mathrm{S} / \mathrm{N}$ values were $\geq 2$ (21).

Evaluation of analytical sensitivity and specificity of Con A-S-ELISA. A purified IBV preparation and four different batches of allantoic fluids infected with IBV M41 strain had their infectious titres in 10-day-old embryonated SPF eggs determined, as described (20). Virus titers were calculated and expressed in 50\% embryonic infectious doses $/ \mathrm{mL}\left(\mathrm{EID}_{50} / \mathrm{mL}\right)(25)$. Such antigen suspensions were also titrated in Con A-S-ELISA by assaying them in twofold serial dilution (1:2 to 1:1024).

The analytical sensitivity of each antigen suspension corresponded to the Log of the reciprocal of the highest dilution which gave the cut-off value of the reaction $(\mathrm{S} / \mathrm{N}=2)$. The $\mathrm{EID}_{50}$ mean $/ \mathrm{mL}$ was calculated from the individual values to determine the minimal amount of IBV detected by Con A-S-ELISA.

The analytical specificity of the Con A S-ELISA was analyzed using different antigen suspensions made up of homologous IBV vaccine strains (M41, H 52 and H 120), heterologous reference strains (Arkansas 99, IOWA 97) and heterologous field viruses (A034 and UEL-236), as well as other avian viruses non-related to IBV such as Newcastle disease virus (NDV, LaSota vaccine strain), Gumboro disease virus (GDV, Lukert vaccine strain) and avian pneumovirus (APV, PL-21 vaccine strain).

The specific interaction of mannoside oligosaccharides of IBV glycoproteins with Con A was also assessed by adding different amounts of a competitor, methyl- $\alpha$-D-manno-piranoside to the IBV antigen suspension in the second step of the Con A-S-ELISA and performing the reaction as described before. The percentages of inhibition (PI) exerted by each concentration of this competitor were calculated, according to the formula: $\mathrm{PI}=\mathrm{A} / \mathrm{B} \times 100$, where $\mathrm{A}=\mathrm{OD}$ mean $\mathrm{ob}$ tained in the presence of methyl- $\alpha$-D-manno-piranoside and $\mathrm{B}=\mathrm{OD}$ mean obtained in the absence of this competitor.

Con A-S-ELISA for antibody detection. The Con AS-ELISA for the quantification of chicken anti-IBV antibody was carried out following the same protocol used for IBV antigen detection, except that a standard non-purified IBV antigen suspension from $\mathrm{AF}$ infected with M41 strain was added in a previously determined optimum dilution onto the Con A pre-coated microplate wells and the reaction was incubated for $1 \mathrm{~h}$ at $37^{\circ} \mathrm{C}$. After washing, the test chicken serum samples in their optimum dilution, as well as the positive and negative reference chicken sera, prepared in PBST-SM 10\% were added and the microplates were incubated for $1 \mathrm{~h}$ at $37^{\circ} \mathrm{C}$. 
Table 1. Frequency of IBV Detection in Tissue Samples from Experimentally Infected Chickens Before and After Chicken Embryo Egg Passage by Con A-S-ELISA

\begin{tabular}{|c|c|c|c|c|c|c|c|}
\hline \multirow[b]{3}{*}{ Groups } & \multicolumn{7}{|c|}{ Number positive/number tested } \\
\hline & \multicolumn{4}{|c|}{$\begin{array}{c}\text { Con A-S-ELISA, } \\
\text { chicken embryo egg passage }\end{array}$} & \multicolumn{3}{|c|}{$\begin{array}{c}V I, \\
\text { chicken embryo egg passage }\end{array}$} \\
\hline & Before & After 1st & After $2 n d$ & After $3 r d$ & After 1 st & After $2 n d$ & After $3 r d$ \\
\hline Infected & $3 / 28^{a}$ & $14 / 28$ & $16 / 28$ & $16 / 28$ & $0 / 28$ & $0 / 28$ & $16 / 28$ \\
\hline Control & $0 / 12$ & $0 / 12$ & $0 / 12$ & $0 / 12$ & $0 / 12$ & $0 / 12$ & $0 / 12$ \\
\hline Total & $3 / 40^{\mathrm{a}}$ & $14 / 40$ & $16 / 40$ & $16 / 40$ & $0 / 40$ & $0 / 40$ & $16 / 40$ \\
\hline
\end{tabular}

${ }^{a}$ Values were statistically different in comparison with VI (after 3rd; $p \leq 0.05$ Fisher's exact test).

The anti-chicken IgG peroxidase conjugate and the development of color reaction steps were performed as described above for the IBV antigen detection. ODs were measured as stated before. For each test serum sample the mean $\mathrm{OD}\left(\mathrm{OD}_{\mathrm{MTS}}\right)$ was expressed in relation to the positive reference serum mean $\mathrm{OD}\left(\mathrm{OD}_{\mathrm{MPRS}}\right)$ and the negative reference serum mean $\mathrm{OD}\left(\mathrm{OD}_{\mathrm{MNRS}}\right)$ as a sample to positive ratios $(\mathrm{S} / \mathrm{P})$, according to the formula $\mathrm{S} / \mathrm{P}=\mathrm{OD}_{\mathrm{MTS}}-\mathrm{OD}_{\mathrm{MNRS}} / \mathrm{OD}_{\mathrm{MPRS}}-\mathrm{OD}_{\mathrm{MNRS}} . \quad$ The cut-off point (CTP) was determined by two-graph receiver operating characteristic (TG-ROC) analysis $(11,27)$. The CTP (S/P value) corresponded to the inter- section point where the curves of sensitivity $(\mathrm{Se})$ and specificity ( $\mathrm{Sp}$ ) of the Con A-S-ELISA were equivalents. Test serum samples were classified as positive when S/P values were $\geq$ cut-off of Con A-S-ELISA.

Reproducibility of Con A-S-ELISA. The reproducibility of Con A-S-ELISA for antigen or antibody detection were determined by repeated titration of one antigen or one serum sample; respectively, allantoic fluid infected with IBV M41 or chicken anti-IBV hyperimmune serum, during the processing of the test samples. The $\mathrm{S} / \mathrm{N}$ and $\mathrm{S} / \mathrm{P}$ values obtained were submitted to variance analysis.

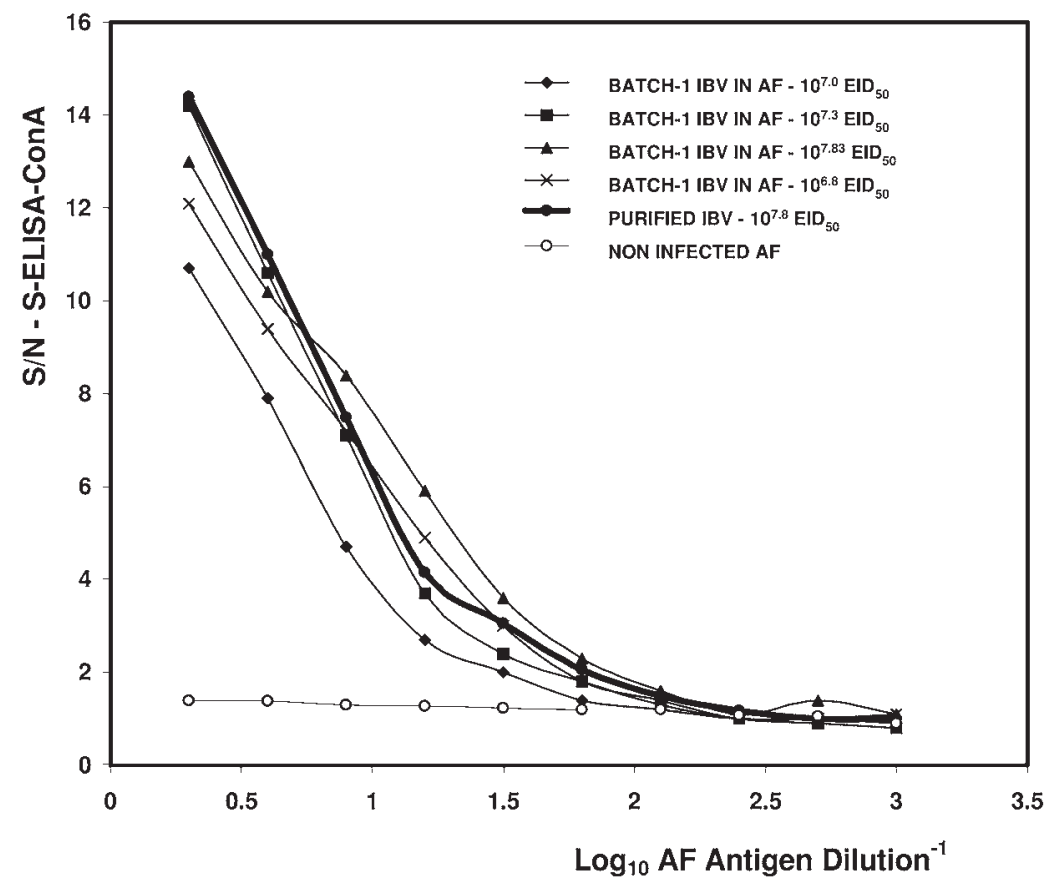

FIG. 1. Detection limits of Con A S-ELISA determined for four batches of allantoic fluid infected with IBV M41 strain containing different $\mathrm{EID}_{50} / \mathrm{mL}$ and a purified preparation of this viral strain. A non-infected SPF AF sample was assayed as a negative IBV antigen control. 
Indirect ELISA. Serum antibody titers were also determined using a commercial indirect-ELISA (I-ELISA) kit (Kirkegaard \& Perry Laboratory, Inc., Gaithersburg, MD) and following the manufacture's instructions. The titres were calculated as Log 1/serum dilution from the $\mathrm{S} / \mathrm{P}$ ratios, as recommended the kit instructions.

Statistical analysis. The non-parametric Fisher's exact test was applied for comparative analysis between the frequency of IBV detection in Con A-S-ELISA and VI test. The anti-IBV antibody levels detected by Con A-SELISA and the commercial I-ELISA were also statistically compared by linear regression analysis. The significance of the correlation coefficients (Pearson $r$ ) was established using the Student Test and the agreement was calculated by Kappa $(\kappa)$ method. The relative sensitivity and specificity, predictive values and accuracy for these methods were also determined. Fisher's exact test was used to compare the sensitivity and the specificity of the two tests. GraphPad Prism 3.00 for Windows (GraphPad, San Diego, CA) and S.A.S. softwares (S.A.S. Institute Inc., Cary, NC) were used for the statistical calculations.

\section{RESULTS}

IBV antigen detection. Maximum discrimination between positive and negative IBV samples in crude AF preparations were obtained, in the checkerboard titration, using $0.125 \mathrm{mg} / \mathrm{mL}$ of Con $\mathrm{A}, 1 / 200$ of detector antibody and 1/2000 of immune-enzymatic conjugate. The presence of IBV in AF from infected embryonated chicken eggs or tissue samples taken from experimentally infected chickens was detected by Con A-S-ELISA and the results compared with VI test (Table 1). Con A-S-ELISA detect directly IBV antigens in only three samples. Nevertheless, after the first passage in embryonated eggs the assay detected the majority of positive tissue samples and after the second passage, there was a complete agreement with VI, which required three embryo passages to confirm the diagnosis (Table 1).

All IBV vaccine strains (M41, H120 and H52) and the four heterologous IBV viruses (Arkansas 99, Iowa97, A034, and UEL-236) showed high S/N values in the Con A-S-ELISA, indicating that this assay presents a high degree of cross-reactivity for the detection of distinct IBV strains (Fig. 1). Non-related IBV viruses (NDV, GDV and APV) as well as non-infected negative control tissue or AF samples gave no positive signals in Con A-SELISA (S/N < 2) (Fig. 1).

The methyl- $\alpha$-D-manno-piranoside competes, in a dose-response manner, with IBV antigens to combine to Con A adsorbed in the solid phase of the microplate wells (Fig. 2). The reproducibility of Con A-S-ELISA for IBV detection was high, demonstrating a coefficient of variation of $5.8 \%$.

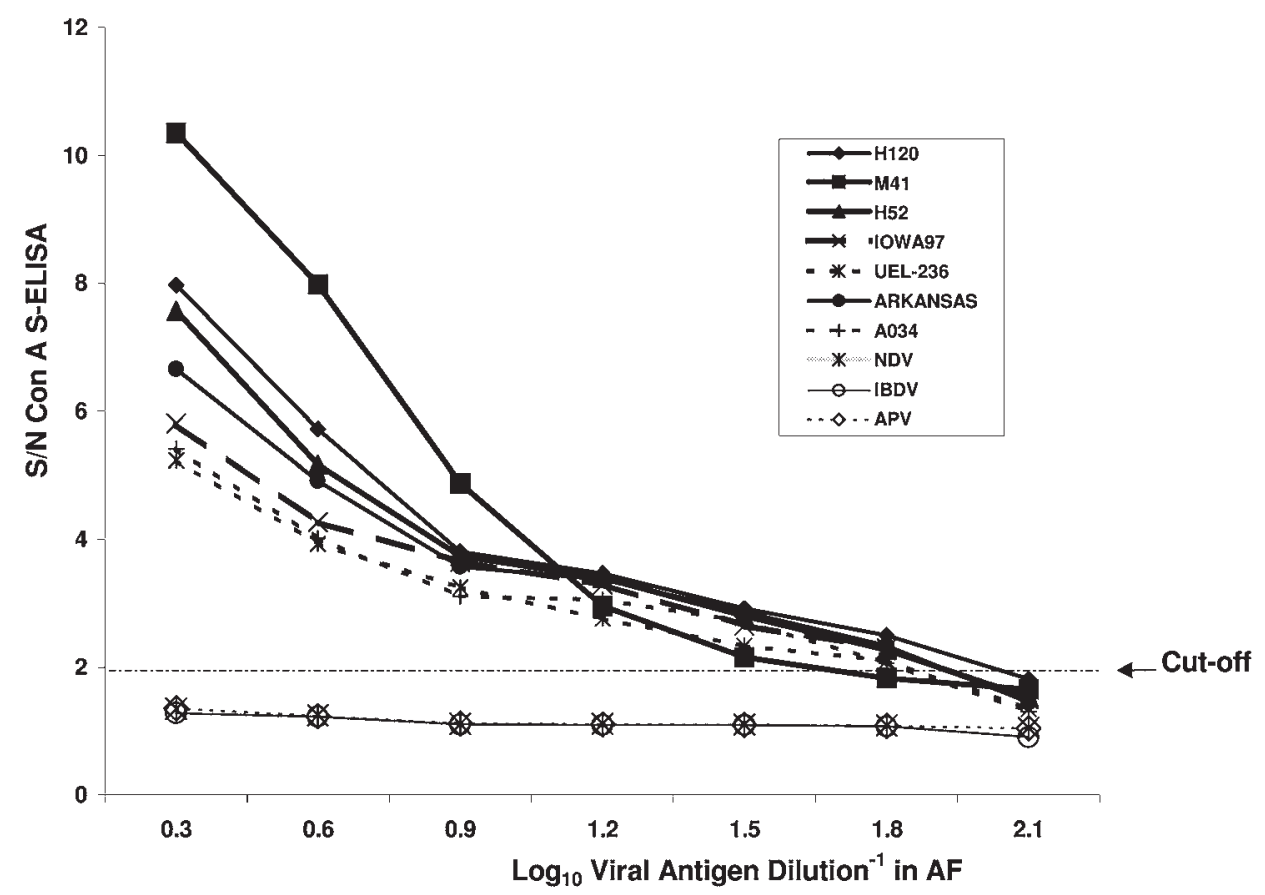

FIG. 2. Reactivity to homologous and heterologous IBV virus strains and IBV non-related viruses Newcastle disease virus (NDV), Gumboro disease virus (GDV), and avian pneumovirus (APV) in Con A S-ELISA, using as detector antibody an antiIBV M 41 chicken polyclonal antiserum. 


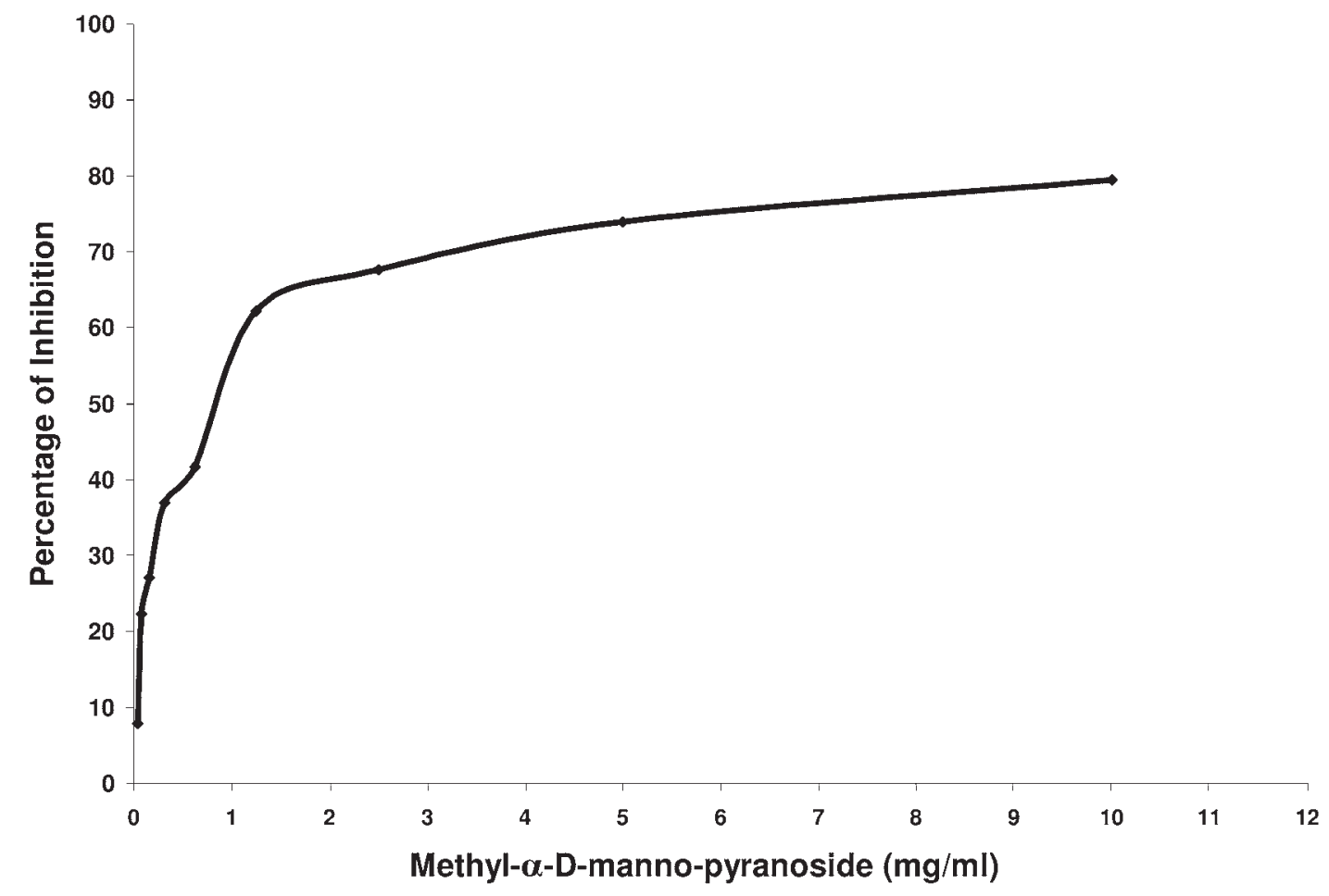

FIG. 3. Inhibition of IBV reactivity in Con A S-ELISA mediated by methyl-alfa-D-manno-pyranoside.

Detection limits of IBV M41 strain in Con A-S-

ELISA. There were no statistical differences $(p=0.18)$ between the results obtained in the titration of four different AF batches infected with IBV M41 strain, as well as the purified IBV preparation (Fig. 3). The minimum amount of IBV detected by Con A-S-ELISA corresponded to an average $10^{5.5} \mathrm{EID}_{50} / \mathrm{mL}$ and ranged from $10^{5.1}$ to $10^{5.9} \mathrm{EID}_{50} / \mathrm{mL}$.

Anti-IBV antibody detection by Con A S-ELISA. Results from the checkerboard titration of the reagents demonstrated the same optimum concentration for Con A $(0.125 \mathrm{mg} / \mathrm{mL})$ and the immune-enzymatic conjugate (1/2000), whereas optimal dilutions of $1 / 5$ and $1 / 100$ were found for IBV-infected AF antigen suspension and for single dilution of chicken sera, respectively. The coefficient of correlation between the Con A-S-ELISA and IELISA were highly significant in linear regression analysis $(r=0.85, p<0.0001)$ (Fig. 4). The determination of the cut-off point by TG-ROC analysis using sera from vaccinated and unvaccinated chicken is represented in the Figure 5. The intersection point of the two curves indicates, at the cut-off point of 0.104 (S/P value), that Con A-S-ELISA presents relative sensitivity (Se) and specificity (Sp) of approximately 93\% (point of equivalence). This cut-off point was selected based on count data (nonparametric approach). The accuracy level for this analysis was $95 \%$. Thereafter, $\mathrm{S} / \mathrm{P} \geq 0.104$ was regarded as
anti-IBV positive serum and lower $\mathrm{S} / \mathrm{P}$ values $(<0.104)$ were considered negative serum for IBV antibodies.

The relationship between Con A-S-ELISA and IELISA is shown in Table 2. The relative sensitivity of Con A-S-ELISA was 93\%, and specificity was $96 \%(p<$

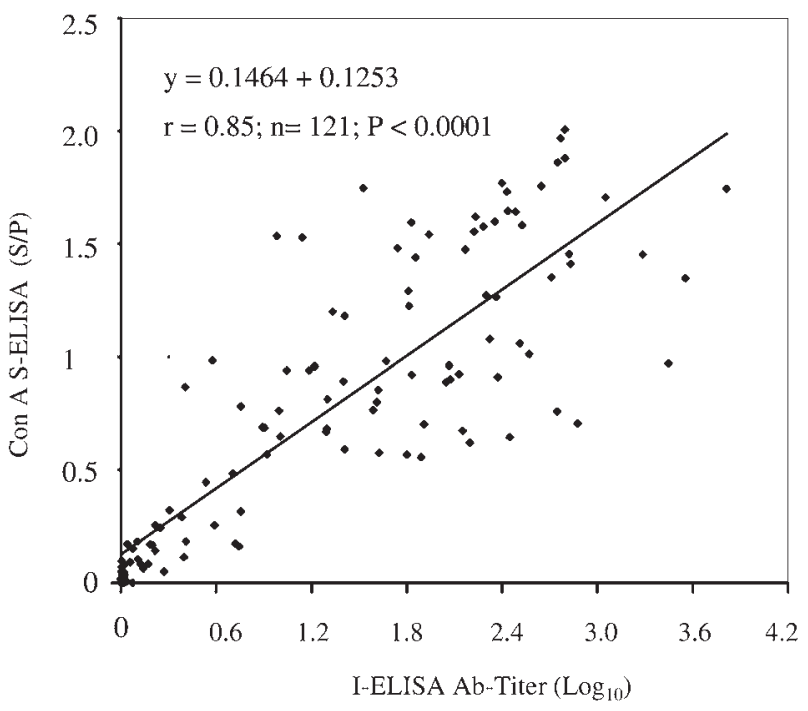

FIG. 4. Correlation between antibody levels $(\mathrm{S} / \mathrm{P})$ obtained in the Con A-S-ELISA and antibody titers $\left(\log _{10} 1 /\right.$ serum dilution) determined in commercial I-ELISA. 


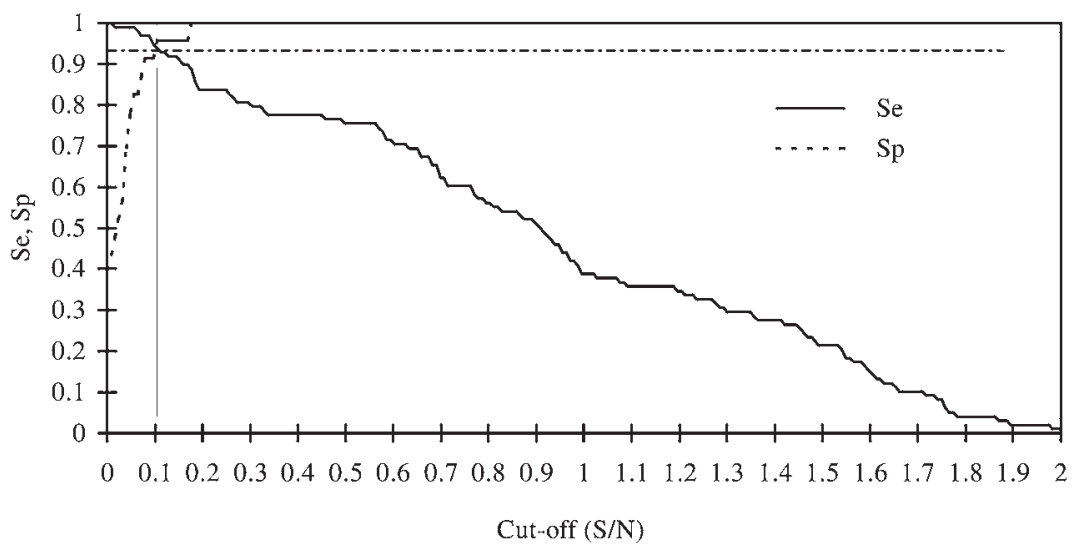

FIG. 5. Curves of relative sensitivity ( $\mathrm{Se}$ ) and specificity $(\mathrm{Sp})$ of the Con A-S-ELISA using TG-ROC analysis. The intersection point of the two curves indicates the cut-off point $(\mathrm{S} / \mathrm{P}=0,104)$ at $\mathrm{Se}=\mathrm{Sp}=0.93$ (dotted horizontal line).

0.0001); the accuracy between the two tests was $93.39 \%$ and the positive and negative predictive values were, respectively $98.91 \%$ and $75.86 \%$. A good agreement between these serological methods was found $(k=0.80$, $p<0.0001)$. The reproducibility of Con A-S-ELISA for anti-IBV antibody detection showed a coefficient of variation of $5.4 \%$.

Antibody levels in Con A-S-ELISA were also determined for serum samples collected from chickens submitted to infection and re-infection with M41 strain of IBV over a period of 63 days. A typical seroconversion curve of antibody production was found after IBV infection (Fig. 6). Chickens infected at 3 weeks of age with M41 strain of IBV showed a consistent increase in anti-viral antibody levels, measured as mean S/P ratios in Con A-S-ELISA, from 5 to 63 days post-infection (PI) and a further rise in anti-IBV antibody levels was detected 2 weeks after these birds were re-infected (Fig. 6).

Table 2. Comparative Results Between the I-ELISA AND Con A-S-ELISA to Detect Anti-IBV Antibodies in Chicken Sera

\begin{tabular}{lccr}
\hline & \multicolumn{2}{c}{ I-ELISA } & \\
\cline { 2 - 3 } Con A-S-ELISA & Positive & Negative & Total \\
\hline Positive & 91 & 1 & 92 \\
Negative & 7 & 22 & 29 \\
Total & 98 & 23 & 121 \\
\hline
\end{tabular}

Relative sensitivity $=91 / 98 \times 100=92.86 \%$.

Relative specificity $=22 / 23 \times 100=95.65 \%$.

Accuracy $=(91+22) / 121 \times 100=93.39 \%$.

Positive predictive value $=91 /(91+1) \times 100=98.91 \%$.

Negative predictive value $=22 /(7+22) \times 100=75.86 \%$.

\section{DISCUSSION}

The lectin Con A, which binds specifically to IBV glycoproteins $\mathrm{S}$ and $\mathrm{M}$ (13), was used herein as trapping reagent in the S-ELISA for the detection of either IBV antigens or anti-viral specific antibodies. The specific interaction of this lectin to mannoside oligosaccharides present in the structure of these glycoproteins was confirmed by the inhibition of IBV reactivity in Con A SELISA induced by the methyl- $\alpha$-D-manno-piranoside in a concentration range from 0.1 to $2.5 \mathrm{mg} / \mathrm{mL}$.

The detection limit of IBV in the Con A-S-ELISA $\left(10^{5.5} \mathrm{EID}_{50} / \mathrm{mL}\right)$ was similar to the levels reported previously for conventional S-ELISA and competitive ELISA $(1,15,19,34)$. However, this level is higher than the detection limit found, in monoclonal antibody-SELISA (12), probably because the characteristics of antiIBV monoclonal antibodies (mAbs) used as capture reagent by these authors. The non-specific protein or carbohydrate components present in the AF from crude IBV antigen suspensions seem to exert no relevant effects in the specificity and sensitivity of Con A S-ELISA, since no significant difference was observed between the reactivity of the purified IBV antigen preparation and those recorded for the crude IBV antigen batches (Fig. 1).

Three homologous and four heterologous IBV strains were effectively detected by the Con A S-ELISA, suggesting that the mannoside oligosaccharides found in the S and M glycoproteins of M41 IBV strain (13) are conserved among these different IBV strains. Moreover, the polyclonal antibodies present in the detector antibody reagent used in this assay may play a relevant role in the genesis of such results, because these antibodies were obtained from chickens multi-immunized with IBV M41 strain and are expected to have a broad spectrum of crossreactivity. The interactions of the avian heterologous 


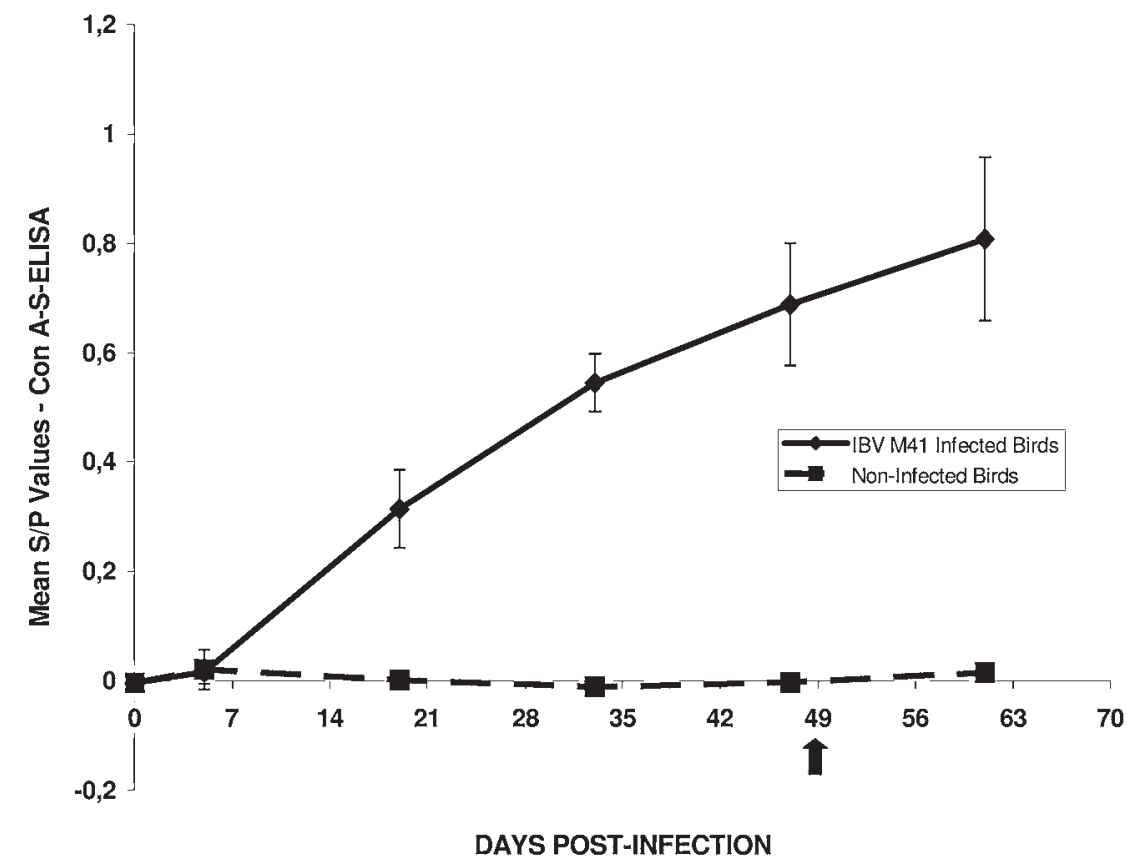

FIG. 6. Time-course of anti-IBV antibody responses determined by Con A-S-ELISA (mean S/P values) of chickens experimentally infected, at 21 days of age and re-infected at 70 days of age (arrow) with M41 strain of IBV and of non-infected chickens from the negative control group.

viruses non-related to IBV, such as NDV, GDV and APV with the lectin (Con A) though possible, were not detected in this ELISA format, since the last viruses showed no relevant reactivity in the Con A-S-ELISA. These results may also be ascribed to the absence of non-specific reactivity to these viruses in detector antibody preparation that was used.

Con A-S-ELISA did not detect IBV antigens in trachea and lung homogenates easily, but it was highly efficient in detecting this virus after one embryo passage, depicting a general performance not statistically different from the VI test and showing a high reproducibility (Table 1). Furthermore, the Con A-S-ELISA must be considered as sensitive and specific as an S-ELISA applied for the detection of IBV antigen by Naqi et al. (21), using a set of mAbs against the different IBV proteins, as capture antibodies.

Antibodies from vaccinated or infected chickens were detected by Con A-S-ELISA and the results were compared with the more widely adopted commercial kit of I-ELISA for antibody detection. The coefficient of correlation between these two assays was high ( $r=$ 0.85 ) and similar to those coefficients found for different methods of ELISA compared with in-house or commercial I-ELISA, S-ELISA, or I-ELISA using recombinant S1-antigen, or even with virus-neutralization or haemagglutination-inhibition tests $(2,3,4,18,24$, 28,29).
The TG-ROC analysis of the results obtained by the Con A-S-ELISA and I-ELISA used to titer anti-IBV antibodies in serum samples from vaccinated, experimentally infected or unvaccinated chickens defined a suitable cut-off value of Con A-S-ELISA, which permitted a clear discrimination between anti-IBV positive and negative serum samples and the achievement of better results when this test is used for the quantification of chicken anti-IBV antibodies. Thus, the Con A-S-ELISA proved to be adequate, either for anti-IBV antibody detection or for monitoring the antibody responses to IBV which were elicited by infection or vaccination with this virus. Such performance can not be considered distinct from the commercial or in-house I-ELISAs which have demonstrated their efficacy when used for the same purposes $(2-4$, 24,28,31,33).

The Con A-S-ELISA showed high sensitivity and specificity for detection of IBV antigens or anti-viral specific antibodies, as the Lectin-ELISAs applied before for the diagnosis of retroviruses. Such assays used mannoside-specific oligosaccharides lectins from Narcissus pseudonarcissus (NPL) or Galanthus nivalis (GNL) to detect envelope glycoprotein of HIV or human specific antibodies against this antigen, or alternatively, feline antibodies to glycoproteins of FIV $(26,30)$. The promising results of the lectin-ELISAs, including our assay, can be attributed to the fact that either lectins or antibodies can be used to characterize and quantity glycoproteins, but 
the former substances are particularly most appropriate for analysis of glycosylated molecules. Furthermore, lectins generally have rather broader specificity than antibodies and only react specifically with carbohydrate groups (17).

This is the first paper proposing an application of a lectin (Con A) in a format of S-ELISA for the detection of avian coronavirus antigen or specific antibodies to this virus. Con A-S-ELISA offers several advantages. It is easy to perform, allowing the screening of a large number of samples and it can be considered rapid, even when the infected tissue sample needs one or two embryo passages, since a minimum of three embryo passages are usually required to confirm the IBV diagnosis by VI (10). Furthermore, the Con A-S-ELISA can be applied alternatively for antigen detection, or measuring of specific anti-IBV antibodies; using the same basic set of reagents and taking into account the fact of the lectin Con A acts as an efficient alternative for the laborious, time-consuming and expensive preparation either of purified IBV particles, or the specific anti-IBV capture antibodies to laboratory animals.

In conclusion, the Con A-S-ELISA is a saving-cost diagnostic procedure, as it has the concept of simultaneous antigen and antibody detection, which is of great importance for IBV diagnostic, because there is a definite need to continue testing for early infection, or to detect antibody responses against this virus after infection or vaccination in larger flocks.

\section{ACKNOWLEDGMENTS}

We thank Fundação de Amparo à Pesquisa do Estado de São Paulo (FAPESP; 96/12599-7, 97/108430-0, 97/14619-8, and 01/14650-3), Conselho Nacional de Desenvolvimento Científico e Tecnológico (CNPq; 520832/96-5-NV and 477140/2003-3), for financial support of this study, and Clovis de Oliveira and Victorio A. Chiaramonte (Setor de Avicultura, Merial) for supplying embryonated SPF chicken eggs.

\section{REFERENCES}

1. Bronzoni, R.V.M., A.A. Pinto, and H.J. Montassier. 2001. Detection of infectious bronchitis virus in experimentally infected chickens by an antigen-competitive ELISA. Avian Pathol. 30:67-71.

2. Cardoso, T.C., H.J. Montassier, M.C.M. Galletti, and A.A. Pinto. 1996. Evaluation of an indirect ELISA method for the detection of chicken antibodies against infectious bronchitis virus. Rev. Microbiol. 27:64-69.

3. Cardoso, T.C., H.J. Montassier, M.C.E. Galletti, and A.A. Pinto. 1996. Development and application of a sandwich
ELISA to measure chicken antibodies to infectious bronchitis virus. Virus Rev. Res. 1:75-80.

4. Cardoso, T.C., R.L. Moro-Sousa, C. Oliveira, G. Stringhini, and A.A. Pinto. 1999. A liquid phase blocking ELISA for the detection of antibodies against infectious bronchitis virus. Braz. J. Med. Biol. Res. 32:747-752.

5. Cavanagh, D. 1981. Structural polypeptides of coronavirus IBV. J. Gen. Virol. 53:93-103.

6. Cavanagh, D. 1983. Coronavirus IBV: further evidence that the surface projections are associated with two glicopolypeptides. J. Gen. Virol. 64:1787-1791.

7. Cavanagh, D., and S.A. Naqi. 1997. Infectious bronchitis, pp. 511-526. In: B.W. Calnek, H.J. Barnes, C.W. Beard, W.M. Reid, and H.W. Yoder, Jr. (eds.), Diseases of Poultry, 10th ed. Iowa State University Press, Ames.

8. Garcia, Z., and R.A. Bankowski. 1981. Comparison of a tissue-culture virus neutralization test and enzyme-linked immunosorbent assay for a measurement of antibodies to infectious bronchitis. Avian Dis. 25:121-30.

9. Gilljam, G. 1993. Envelope glycoproteins of HIV-1, HIV2 and SIV purified with Galanthus nivalis agglutinin induce strong immune response. AIDS Res. Hum. Retrovirol. 9:431-438.

10. Gough, R.E., D.J. Alexander, S.A. Collins, and W.J. Cox. 1988. Routine virus isolation or detection in the diagnosis of diseases in birds. Avian Pathol. 17:893-906.

11. Greiner, M., D. Sohr, and P. Göbel. 1995. A modified ROC analysis for the selection of cut-off values and the definition of intermediate results of serodiagnostic tests. J. Immunol. Methods 185:123-132.

12. Ignjatovic, J., and F. Ashton. 1996. Detection and differentiation of avian infectious bronchitis virus using monoclonal antibody-based ELISA. Avian Pathol. 25:721-736.

12. Lai, M.M.C., and D. Cavanagh. 1997. The molecular biology of coronaviruses. Adv. Virus Res. 48:1-77.

13. Lancer, J.A., and C.R. Howard. 1980. The polypeptides of infectious bronchitis virus (IBV-41 strain). J. Gen. Virol. 46:349-361.

14. Leathem, A.J., and S.A. Brooks. 1998. Light microscopy: overview and basic methods, pp. 3-20. In: J.M. Rhodes and J.D. Milton (eds.), Lectin Methods and Protocols. Humana Press, Totowa, NJ.

15. Lougovskaia, N.N., A.A. Lougovskoi, Y.A. Bochkov, G.V. Batchenko, N.S. Mudrak, V.V. Drygin, A.V. Borisov, V.V. Borisov, and A.A. Gusev. 2002. Detection and estimation of avian infectious bronchitis virus antigen by a novel indirect liquid-phase blocking enzyme-linked immunosorbent assay using chicken and rabbit affinity purified immunoglobulins. Avian Pathol. 31:549-557.

16. Marquardt, W.W., D.B. Snyder, and B.A. Schlotthober. 1981. Detection and quantification of antibodies to infectious bronchitis virus by enzyme-linked immunosorbent assay. Avian Dis. 25:713-722. 
17. Milton, J.D., and J.M. Rhodes. 1998. Quantification of intestinal mucins, pp. 255-261. In: J.M. Rhodes, and J.D. Milton (eds.), Lectin Methods and Protocols. Humana Press, Totowa, NJ.

18. Mockett, A.P.A., and Darbyshire, J.H. 1981. Comparative studies with an enzyme-linked immunosorbent assay (ELISA) for antibodies to avian infectious bronchitis. Avian Pathol. 10:1-10.

19. Nagano, H., M. Tsuchimoto, T. Hohdatsu, T.I. Yamagami, S.Y. Eiguchi, Y. Tanaka, and H. Yamagishi, 1990. Enzyme-linked immunosorbent assay for the detection of infectious bronchitis virus (IBV) antigen with monoclonal antibody. Jpn. J. Vet. Sci. 52:657-659.

20. Naqi, S.A. 1990. A monoclonal antibody-based immunoperoxidase procedure for rapid detection of infectious bronchitis virus in infected tissues. Avian Dis. 34:893-898.

21. Naqi, S.A., K. Karaca, and B. Bauman. 1993. A monoclonal antibody-based antigen capture enzyme-linked immunosorbent assay for identification of IBV serotypes. Avian Pathol. 22:555-564.

22. Ndifuna, A., A.K. Waters, M. Zhou, and E.W. Collison. 1998. Recombinant nucleocapsid protein is potentially an inexpensive, effective serodiagnostic reagent for infectious bronchitis virus. J. Virol. Methods 70:37-44.

23. Parker, N., C.A. Makin, C.K. Ching, D. Eccleston, O.M. Taylor, J.D. Milton, and J.M. Rhodes. 1992. A new enzyme-linked lectin/mucin antibody sandwich assay (CAM 17.1/WGA) assessed in combination with CAM 19-9 and peanut lectin binding assay for the diagnosis of pancreatic cancer. Cancer 70:1062-1068.

24. Perrota, C., C. Furtek, R.A. Wilson, B.S. Cowen, and R.J. Eckroade. 1988. A standardized enzyme-linked immunosorbent assay for infectius bronckitis virus: comparison with haemagglutination-inhibition and virus-neutralization assays for measuring protective antibody levels in chickens. Avian Dis. 32:451-460.

25. Reed, L.J., and A. Müench. 1938. A simple method of estimating 50\% end points. J. Hygien. 27:193-197.

26. Sibille, P., A. Avraméas, A. Moraillon, J. Richardson, P. Sonigo, G. Pancino, and A.D. Strosberg. 1995. Comparison of serological tests for the diagnosis of feline immunodeficiency virus infection of cats. Vet. Microbiol. 45:259-267.

27. Souza, R.L.M., H.J. Montassier, and A.A. Pinto. 2000. Detection and quantification of antibodies to Newcastle dis- ease virus in ostrich and rhea sera using a liquid phase blocking enzyme-linked immunosorbent assay. Clin. Diagn. Lab. Immunol. 7:944-947.

28. Thayer, S.G., P. Villegas, and O.J. Fletcher. 1987. Comparison of two commercial enzyme-linked-immunosorbent assay and conventional methods for avian serology. Avian Dis. 31:120-124.

29. Wang, C.-H., C.-C. Hong, and J.C.H. Seak. 2002. An ELISA for antibodies against infectious bronchitis virus using an S1 spike polypeptide. Vet. Microbiol. 85:333-342.

30. Weiler, B.M., H. Schäcke, M. Bachmann, L. Brigido, M. Gilbert, J. Mills, E. Mattehes, J.M.S. Forrest, and W.E.G. Müller. 1991. Human immunodeficiency virus: novel enzyme-linked immunoassays for quantitation of envelope glycoprotein 120. J. Virol. Methods 32:287-301.

31. Wit, J.J. de, F.G. Davelaar, and W.W. Braunius. 1992. Comparison of the enzyme-linked-immunosorbent assay, the haemagglutination inhibition test and the agar gel precipitation test for the detection of antibodies against infectious bronchitis and Newcastle disease in commercial broilers. Avian Pathol. 21:651-658.

32. Wit, J.J. de, G. Koch, A. Kant, and D.J. Van Rozelaar. 1995. Detection by immunofluorescence assay of serotypespecific and group specific antigens of infectious bronchitis virus in tracheas of broilers with respiratory problems. Avian Pathol. 24:465-474.

33. Wit, J.J. de, D.R. Mekkes, B. Kouwenhoven, and J.H.M. Verheijden. 1997. Sensitivity and specificity of serological tests for infectious bronchitis virus antibodies in broilers. Avian Pathol. 26:105-118.

34. Yagyu, K., and S. Ohta. 1987. Enzyme-linked immunosorbent assay for the detection of infection bronchitis virus antigens. Jpn. J. Vet. Sci. 49:757-763.

Address reprint requests to: Dr. Helio J. Montassier Faculdade de Ciências Agrárias e Veterinárias Dept. de Patologia Veterinária Universidade Estadual Paulista Rodovia Prof. Paulo Donato Castellane, Km 05 14884-900, Jaboticabal, SP, Brazil

E-mail: heliojm@fcav.unesp.br

Received March 20, 2005; accepted May 24, 2005. 